\title{
An Empirical Study of Growth of Slum Population in India
}

\author{
Dr. S. Kumar Swami
}

Lecturer in Political Science, Kamala Nehru Women's College, Bhubaneswar - 9

\begin{abstract}
In India due to rapid industrialization, lack of employment opportunities in rural areas, low wages, ineffective land reforms etc about one third of the population live in slums and the like conditions in urban areas .Likewise about 27 percentage of population occupy only 5 percentage of the urban land area. These unimproved slums are characterized by overcrowding dilapidated structures, Unhygienic living conditions, grossly inadequate basic amenities, unplanned layouts and poor accessibility. Hence slum dwellers need to be enlightened on their potential contributions for ensuring sustainable development in the urban areas. Therefore there is necessity to promote policies that would help to improve their social and economic life and to reduce the imbalances in income level and standard of life.
\end{abstract}

Keywords: Growing slum population, rapid industrialization, unhygienic, poor accessibility, promote policies, enlighten of the poor.

India has emphatically embraced the planned development for improving social and economic life of the people during the post independence period. Development has been achieved to a certain extent, but poverty, illiteracy, unemployment, malnutrition and such other human problems have not been eradicated and they have become major areas of concern for the policy makers, planners, leaders, administrators and, development practitioners, as the achievements have not been commensurate with the expectations. The author argues that although slum dwellers account for 27 percent of the population they occupy only 5 percent of the urban land area. Unimproved slums are characterized by overcrowding, dilapidated structures, unhygienic conditions, grossly inadequate basic amenities, unplanned layouts and poor accessibility. Many colonies have existed in this condition for twenty years or more, becoming progressively more overcrowded by passage of time, and needs immediate attention

In India, there has been tremendous increase in urban population. The total urban population of the country is almost doubled by 1988. By 1991, it was 84.94 million and by March 2001, it had reached 285 million marks. The decadal growth rate of urban population has been $31.2 \%$. The percentage of urban population of the total population of the country stands at $27.8 \%$. In the 1991 census it was $25.7 \%$. The census of 2001 had projected the population to be more than 100 million i.e. $35 \%$ of the total population. The United Nations report on India's urban population was projected at 33 crores in $2001,45.4$ crores in $2010,59.1$ crore in 2020 and 65.8 crores by 2025 against the projected population of 122 crores approximately. India has a spread-over of uneven distribution of urban population in various states. As per census 2011, the urban population of India is 286.11 million which constituted $27.8 \%$ of the total population. The 35 million plus cities contained more than one-third $(37.85 \%)$ of the total urban population. During 1991-2001 decade, the number of million plus cities increased from 23 to 35 and their number was likely to increase to 50 by 2011. It has been estimated that there would be an increase of additional 78 million to the total urban population by 2011. Assuming that a project increase of 39 million in the population has taken place in about 50 million plus cities $(45-50 \%$ of total urban population by 2011), the average increase in population per million plus city would be of the order of 1.2 million during 2001-2011. India is expected to reach 600 million urban populations by 2031 . It is likely to have 87 metropolitan cities by 2031 . From 160 million people in metropolitan cities only in 2011, the population is likely to reach 255 million. In other cities the population is projected to rise from 217 million in 2011 to 343 million by 2031. From a total number of 5161 cities and towns in India in 2001, the number has increased to 7935 cities and towns by 2011. This magnitude is bound to lead to massive problems in managing already overstrained mega/million plus and other cities. 


\section{Dr. S. Kumar Swami}

Urban India is undergoing a process of great transformation in the midst of economic reform, liberalization and globalization. Many cities and towns are fast emerging as centre of growth. It is estimated that by 2025 more than 50 per cent of the country's population will live in cities and towns. This is likely to pose serious problems to urban planners, policy-makers and managers of urban affairs in terms of increased requirement of funds for infrastructure development and management. Despite' significant emphasis laid on improvement of infrastructure development in the successive five year plans, deficiencies in urban infrastructure continue with poor service delivery. A national survey of major "Public Services by Public Affairs" (2002) conducted by central government indicated the poor quality, reliability and effectiveness of basic services in urban local bodies. Accelerated growth of population in large urban centre has been compounded by extremely limited financial resources of the developing countries. This has put a severe strain on their already weak and inadequate basic infrastructure resulting in detonation in all aspects of quality of life at the household, neighborhood and city levels. Because of limited resources and unequal access to civic needs such as shelter, sanitary facilities, safe water, sewerage, solid waste disposal, environmental situation in urban areas becomes grave.

Because of inter-regional and inter-city disparities in access to infrastructure and basic amenities, sharp differences are noticed in the micro-level quality within a city between high income localities and slum/squatter settlements. As a result, the worst affected are the poorer sections. They lack financial resources to compete for service land and adequate housing and therefore, are compelled to occupy illegal settlements in un-serviced lands normally along railway tracks, river-beds/slopes etc. In India, more than $40 \%$ of the populace on an average in the metropolitan cities lives in slum and squatter settlements in vulnerable locations.

In 2011 Census three types of slum i.e. 1 Notified slum, 2.Recognised slum and 3. Identified slum have been recorded. For example if the total Indian slum population is 100 then the notified slum is $34.3 \%$, recognized slum $30.04 \%$ \& identified slum 35.3\% (as per 2011 census) The chart-1 below gives state share of slum population to total slum population of India.

Chart1. Primary Census Abstract for slum $2001 \& 2011$

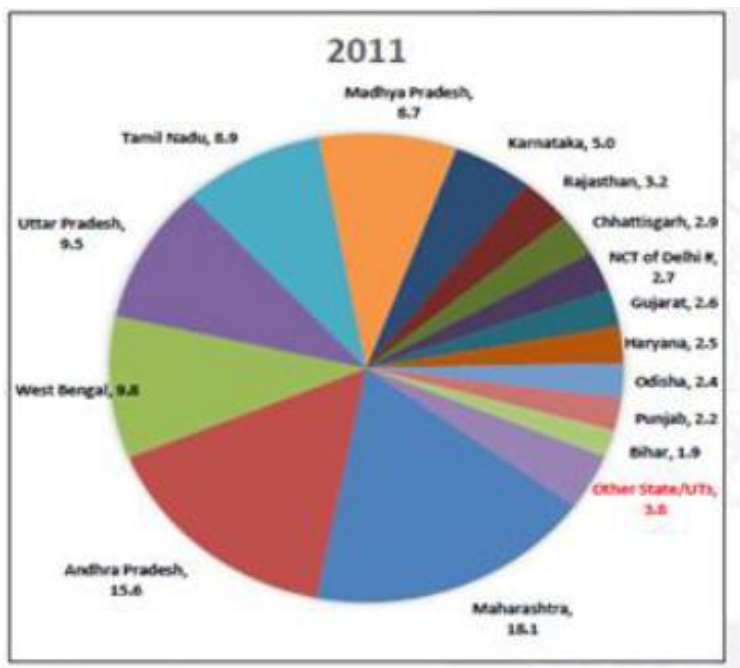

Other States/UT:

4. Reopirted shum less than 1.7

ammu \& Kashmir, Uttarakhand, Mharkhand, Assam, Kerala, Tripura Tripura, Puduchern $\equiv$. Himachal Pradesh, Chandigart $\boldsymbol{x}$, Nagaland, Mizoram, Nagaland, Mizoram, Meghalaya, Sikkim, Arunachal Pradesh. Goa and $A \& N$ istands a

2. State/UTs not reported slum

Manipur, Daman \& DWu a, D \& N Haveli a and Lakshadweep a

Source: Primary Census Abstract for Silum, 201

Office of the Registrar General \& Census Commissioner, India



Other States/UTs includes:

1. Aeoprted slum less thon 1.5

Jammu \& Kashmir, Uttarsihand, Jharkhand, Chandicarh II, Meghalays,

Assam, Assam, Puducherry $a$, Tripura and Kerala

2. Stote/UT's not reported stim

Mimachal Pradesh, Sibim, Arunachal Pradesh, Nagaland, Manipur, Mizoram, Daman \&. Diu $=, D$ \& N Haveli a, Lakshadweep tandA \& $N$ islands a

\section{INDIAN SCENARIO}

For the $1^{\text {st }}$ time in the history of the population census in the country, slum demography has been presented on the basis of actual count in census 2001. After detail analysis it is found that the pattern of growth of cities and proliferation of slums bring out to the four aspects concern. Firstly, movement of low income population into the city and its concentration and growth is an ever increasing phenomenon; estimates indicate that about one third of the population in large cities live in slum or 
slum like conditions and the proportion could be even higher in metros and mega cities. Further, whereas the population in urban settlements is growing at rates between 2 to 3 per cent per annum, the population in the slum and informal settlements in urban areas is estimated to be growing at the rate of 6 to 8 per cent per annum.

Secondly, the proliferation of slums in cities is a result of the inefficiency and weakness of the urban system to respond adequately to meet the shelter requirements of the economically weaker sections, which migrate to the city primarily for economic reasons. In the absence of adequate access to shelter or land, the economically weak migrant population attempts to occupy the vacant lands. The abysmal environmental quality in the slum areas is compounded by the inability and awareness among the slum dwellers to take 'up self help initiatives for improvement.

Thirdly, there is a substantial ignorance and insensitiveness among the city population, in general, and civic administration, in particular, on the significant contribution of the slum dwellers for the overall growth of the urban economy and their self-help initiatives are treated 'insignificant' in the overall growth of the urban economy. Rather than citizens, the slum dwellers are considered as a "civic problem",

\section{CAUSES OF SLum Growth IN INDIA}

In India, the following causes are usually attributed for the origin and growth of slums :-

\section{Industrialization and Consequent Migration of Rural Masses to Urban Areas}

After the attainment of independence, the pace of industrialization has increased in our country and large as well as medium-sized industries have been established in several parts of the country. The industrial concerns have attracted the rural masses for employment. Subdivision of land owing to increase in rural population has resulted in uneconomic holdings and unprofitable agriculture. Periodic famines, floods, pestilences and other calamities have aggravated the problem.

\section{Lack of Employment Opportunities and Livelihood Resources in Rural Areas}

People in rural areas primarily depend upon agriculture which only provides limited seasonal employment. The employment 'potentiality in rural areas is low and it promotes migration of population from rural to urban areas in search of employment opportunities. Therefore lack of employment opportunities in rural areas accelerates the growth of slums in the periphery of the urban conglomerate.

\section{Absence of Adequate Facilities in the Urban Area}

Most of our cities are congested and overcrowded with the lack of civil amenities when people thrown into the cities to work in industries, in construction work, in transport and trading Corporations and they fail to find housing accommodation. If there were thousands of industrial workers without residential facilities they try to make some temporary arrangements near the place of their work. Whenever they find vacant Government land, large number of unhygienic huts spring up near the factories or commercial concerns. These naturally turn into slums because the area is small, proper roads are not available, facilities like electricity; water and toilet do not exist.

\section{Low Wages}

Large number of our industrialized urban workers is unskilled labourers earning low wages. Many of them are employed on temporary basis. They cannot afford to have cement-mortar houses with proper facilities. So, they are forced to live in slums.

\section{In Effective Land Reforms}

The age old practice of land owning \& landless people creates landless labours. The landless labourers are lured and attracted by the wage labour in the Industrial Sector and thereby leave aside the traditional occupations and migrate to Industrial and urban centers to sell their labour. Such migrants no doubt contribute enormously to the growth of slum population in urban.

\section{CONCLUSION}

India, as a developing nation, has emphatically embraced the planned development for improving the social and economic life of its people during the post independence period, in course of the implementation of Seven Five Year Plans development has been achieved to certain extent. However, 


\section{Dr. S. Kumar Swami}

poverty, illiteracy, unemployment, mal-nutrition and such other human problems have not been eradicated and they have posed major areas concern for the policy-makers, social planners, leaders, administrators and, development practitioners, as the achievements have not been commensurate with the expectations. It requires consistent and persistent efforts to achieve long-term plan objectives. As a partial fulfillment of the requirement of the man made planning process there are needs for appropriate diagnosis of problems of people in the contextual societal framework. We do not have adequate knowledge on certain vital aspects of socio-economic concern and for that matter paths of development do not become realistic and need based. The planning for urban development remains incomplete if the problems of slum dwellers are lost sight.

Although slum dwellers account for 27 percent of the population they occupy 5 percent of the urban land area. Unimproved slums are characterized by overcrowding, dilapidated structures, unhygienic conditions, grossly inadequate basic amenities, unplanned layouts and poor accessibility. Many colonies have existed in this condition for twenty years or more, becoming progressively more overcrowded as time goes by. The people have been attracted to this place because of push \& pull factors to earn better living.

\section{BIBLIOGRAPHY}

[1] Karunakar Patnaik, Basic Services and infrastructure development in Local bodies, National and state : Odisha Perspective, Capital Press, Bhubaneswar, 2014.

[2] C. Chandramouli Registrar General \& Census Commissioner, India, Primary Census Abstract Slum, Census of India, 2011.

[3] Census of India, 2001, slum population (640 cities and towns reporting slum) Published by Govt. of India, 2001.

[4] K.K. Mohanti and Manoranjan Acharya, Displaced slum Dwellers of Bhubaneswar and their Rehabilation, Nabakrushna Choudhury Centre for Development Studies, Bhubanes war, 1990.

[5] H.C. Upreti, Urban Slums and Dimensions of Poverty, Pointer Publisher, Jaipur, 2004.

[6] Haarrington Michael, "Old slums and New Slums" in A.R. Desai and Pillai, Slums and Urbanization, Popular Prakashan, Bombay, 1976.

[7] K.C. Sivaramakrishnan, The Slums improvement in Calcutta, Manahor Publications, New Delhi, 1983. 